\title{
Subcutaneous implantation of a ferrocene-mediated glucose sensor in pigs
}

\author{
D.J.Claremont ${ }^{1}$, I. E. Sambrook ${ }^{2}$, C. Penton ${ }^{1}$ and J. C. Pickup ${ }^{1}$ \\ ${ }^{1}$ Division of Chemical Pathology, United Medical and Dental Schools, Guy's Hospital Campus, London and \\ ${ }^{2}$ Food Research Institute, Shinfield, Reading, UK
}

\begin{abstract}
Summary. Miniature, amperometric glucose sensors were constructed using entrapped $1,1^{\prime}$-dimethylferrocene to mediate electron transfer between immobilised glucose oxidase and a carbon base electrode. Electrodes were calibrated in buffered glucose solutions and then implanted in the subcutaneous tissue of anaesthetised, non-diabetic pigs. Subcutaneous tissue glucose concentrations, as measured by the sensor, were about $20 \%$ of blood glucose values, measured by a conventional glucose oxidase assay. After an intravenous $0.07 \mathrm{~mol}$ bolus glucose injection, electrode responses increased with almost no time lag, but the subsequent rates of rise and fall of electrode-
\end{abstract}

measured tissue glucose concentrations were slower than that of the blood values. After an intravenous $0.2 \mathrm{U} / \mathrm{Kg}$ bolus short-acting insulin injection the electrode response was also rapid, but decreased at a slower rate than the blood glucose concentrations. We conclude that this is a feasible technology for future development as an implantable glucose sensor for use in diabetic man.

Key words: Glucose sensor, enzyme electrode, glucose oxidase, ferrocene, diabetes mellitus, subcutaneous tissue.
The introduction of portable, closed-loop insulin infusion systems into clinical diabetes depends on the development of a reliable implantable glucose sensor. Several possible configurations for a glucose sensor have been suggested and are under investigation [1-7], and particular progress has been made in the in vivo evaluation of amperometric enzyme (glucose oxidase) electrodes which involve detection of hydrogen peroxide $[6,7]$. However, an alternative strategy [8] uses an entrapped, organic mediator, such as ferrocene, to transfer electrons from immobilised glucose oxidase to a base electrode. Since oxygen is not the final electron acceptor in this type of glucose sensor, it may have special advantages for in vivo use, such as relative freedom from interference from fluctuating tissue oxygen tensions.

We recently described [9] the construction and in vitro characteristics of a miniature, dimethylferrocenebased glucose sensor. We now report studies in which the sensor was implanted in the subcutaneous tissue of non-diabetic pigs (a species where this tissue is similar to that of man), and responses were compared to conventionally measured blood glucose concentrations.

\section{Materials and methods}

The construction of glucose sensors has been described previously [9]. In brief, $1 \mathrm{~mm}$ wide graphite foil strips (Papyex, Le Carbone, Portslade, Sussex, UK) acted as the base electrode. Supported on epoxy- glass ( $2 \mathrm{~mm}$ thick), $3 \mathrm{~cm}$-long strips were insulated with epoxyresin, except for $10 \mathrm{~mm}$ at one end for enzyme immobilisation and $5 \mathrm{~mm}$ at the other end for electrical contact.

Electrodes were dipped for $10 \mathrm{~min}$ at $20^{\circ} \mathrm{C}$ in $0.2 \mathrm{~mol} / 11,1^{\prime}$-dimethylferrocene (dicyclopentadienyl iron, Strem Chemicals Inc, Newburyport, Mass, USA) in ethanol. After air-drying, electrodes were then placed for $90 \mathrm{~min}$ in $0.06 \mathrm{~mol} / 1$ 1-cyclohexyl-3-(2-morpholinoethyl) carbodiimide p-methyl-toluenesulphonate (Sigma Chemicals, Poole, Dorset, UK) in $0.1 \mathrm{~mol} / 1$ sodium acetate buffer, $\mathrm{pH} 4.5$. Glucose oxidase was then immoblised on the electrodes by dipping in a solution of the enzyme $(4000 \mathrm{IU} / \mathrm{ml}$; Sturge Ltd, Selby, Yorkshire, $\mathrm{UK}$ ), in $0.1 \mathrm{~mol} / 1$ sodium phosphate buffer, $\mathrm{pH} 7.4$, for $18 \mathrm{~h}$ at $4{ }^{\circ} \mathrm{C}$. Electrodes were then rinsed in distilled water and immersed in $2 \%$ (v/ v) glutaraldehyde in $0.1 \mathrm{~mol} / 1$ sodium phosphate buffer, $\mathrm{pH}$ 7.4. Membranes were applied by dip-coating in a solution of $4 \%(\mathrm{w} / \mathrm{v})$ polyurethane ("Estane", BF Goodrich Chemicals Ltd, Hounslow, Middlesex, UK) in dimethylformamide.

Electrodes were stored at $4{ }^{\circ} \mathrm{C}$ in $0.1 \mathrm{~mol} / 1$ sodium phosphate buffer, $\mathrm{pH} 7.4$, containing $0.15 \mathrm{~mol} / 1$ sodium chloride and used within 3 days of manufacture.

Before implantation, electrodes were calibrated in buffered glucose solutions using a thermostatically-controlled cell (volume $10 \mathrm{ml}$ ) set at $39^{\circ} \mathrm{C}$. A two-electrode system was used, with a silver/silver chloride wire as the pseudoreference and the working electrode held at $160 \mathrm{mV}$ using a potentiostat (HB Thomson, Model 251, Newcastleupon-Tyne, UK). Currents were recorded on an LKB Model 2210 chart recorder (LKB, Selsdon, UK). D-glucose solutions were stored for at least $18 \mathrm{~h}$ to allow equibration of $\alpha$ - and $\beta$-anomers, and appropriate concentrations were made in $0.1 \mathrm{~mol} / 1$ sodium phosphate buffer, $\mathrm{pH} 7.4$, containing $0.15 \mathrm{~mol} / 1$ sodium chloride.

For insertion of intravenous catheters for blood sampling and drug administration, male pigs (Large white $\times$ Landrace) weighing $25-30 \mathrm{Kg}$ were anaesthetised with halothane (4-8\% in oxygen). Catheters were inserted through the left and right external jugular 
Table 1. In vitro characteristics of the glucose sensor

\begin{tabular}{ll}
\hline Characteristic & Mean \pm SEM Response \\
\hline $95 \%$ Response time & $13.7 \pm 3.4 \mathrm{~s}$ \\
(5 mmol/1 step increase) & $(n=7)$ \\
$95 \%$ Response time & $40.0 \pm 3.7 \mathrm{~s}$ \\
$(5 \mathrm{mmol} / 1$ step decrease) & $(n=6)$ \\
Current density & $4.6 \pm 0.6 \mu \mathrm{A} / \mathrm{cm}^{2}$ \\
$(0 \mathrm{mmol} / 1)$ & $(n=7)$ \\
Current density & $21.7 \pm 2.5 \mu \mathrm{A} / \mathrm{cm}^{2}$ \\
(5 mmol/1) & $(n=7)$ \\
\hline
\end{tabular}

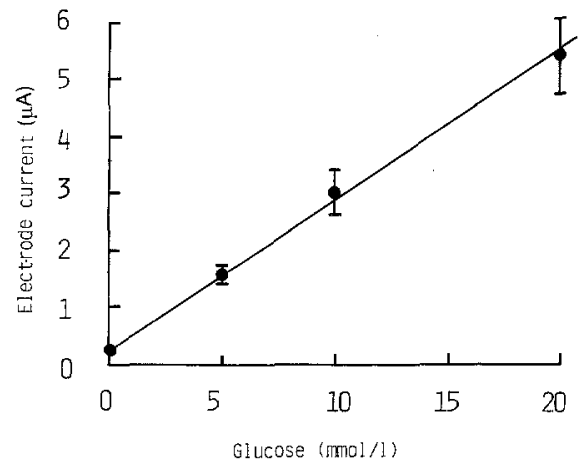

Fig. 1. Mean \pm SEM electrode current $(n=7)$ for pre-implantation calibration in buffered glucose solutions

veins into the anterior vena cava and secured subcutaneously in the neck with ligatures. Full aseptic technique was followed during surgery. Animals were allowed to recover for at least one week following surgery before implantation studies were begun. During this time, catheters were kept patent by once daily flushing with heparinised, sterile $0.154 \mathrm{~mol} / \mathrm{l}$ saline.

Approximately $2 \mathrm{~h}$ after their early-morning feed, six pigs, on separate occasions, were initially sedated by the intravenous administration of $10 \mathrm{mg}$ diazepam together with $0.6 \mathrm{mg}$ atropine. After $5 \mathrm{~min}$, 200-300 mg ketamine hydrochloride (Parke-Davis, Pontypool, U.K.) was injected intravenously and anaesthesia maintained throughout the study by regular administration of ketamine. For insertion of glucose sensing electrodes, an approximately $10 \mathrm{~cm}$ diameter area of skin on the flank of the animal was shaved, sterilised with Pevidine solution (Berk Ltd, Eastbourne, UK) and anaesthetised by the subcutaneous injection of $2 \%$ lignocaine solution. A $16 \mathrm{G}$ needle was used to pierce the skin in the centre of the "ring block", and electrodes were then inserted through this incision into the subcutaneous tissue. Usually, two pre-calibrated sensors were implanted about $5 \mathrm{~cm}$ apart in one animal. The reference electrode was a silver/silver chloride surface electrocardiogram electrode (Medicotest, Rugmarken, Denmark) which was attached to the skin directly above the tip of an implanted sensor. The glucose sensor was under potentiostatic control and responses were recorded, as described above for in vitro calibration.

Serial venous blood samples were taken at intervals of 1-10 min from one of the catheters for measurement of glucose concentration using a glucose oxidase-based analyser (Yellow Springs Instruments model 23M, Yellow Springs, Oh, USA). After a stable electrode response had been achieved (mean time $40 \mathrm{~min}$ ), either $0.07 \mathrm{~mol}(12.5 \mathrm{~g})$ glucose $(50 \%, \mathrm{w} / \mathrm{v})$ or $0.2 \mathrm{U} / \mathrm{Kg}$ Actrapid porcine insulin (Novo Ltd, Basingstoke, UK) were injected intravenously, in random order, and glucose sensor responses recorded and blood samples collected for blood glucose measurement (at least $30 \mathrm{~min}$ in all studies, with a range of 30-60 min). When the blood glucose concentration had returned to baseline and was stable for at least $1 \mathrm{~h}$ the alternative agent (glucose or insulin) was injected. A typical experiment lasted $8 \mathrm{~h}$.

\section{Statistical analysis}

Blood and tissue glucose values in various groups were compared by the Wilcoxon test or Student's $t$-test on logarithmically-transformed data.

\section{Results}

\section{In vitro sensor characteristics}

Table 1 shows the in vitro characteristics of the glucose sensor, i. e. the responses when the electrode was operated in buffered glucose solutions at $39^{\circ} \mathrm{C}$. There was no difference in current outputs between stirred and unstirred solutions, and currents at a given glucose concentration were identical before and after a step increase followed by a step decrease to the same concentration (i.e. there was no hysteresis effect). In a further in vitro experiment to characterise the operating features and mechanism of action of the sensor, we recorded a mean \pm SD current of $13.9 \pm 5.9 \mu \mathrm{A}$ in $5 \mathrm{mmol} / 1$ glucose solution which was reduced to $0.29 \pm 0.01 \mu \mathrm{A}(p<0.001)$ when the dimethylferrocene mediator was omitted from the sensor construction.

Figure 1 shows the mean \pm SEM electrode current for a representative sample of glucose sensors when calibrated in vitro using buffered glucose solutions. Electrode responses were linear up to gravimetrically determined glucose concentrations of at least $20 \mathrm{mmol} / 1$. The mean $\pm S E M$ background current (at $0 \mathrm{mmol} / 1 \mathrm{glu}$ cose concentration) was $0.23 \pm 0.09 \mu \mathrm{A}(7.6 \%$ of the current at $10 \mathrm{mmol} / 1$ ).

\section{In vivo experiments}

Figures 2 and 3 show the mean \pm SEM subcutaneous tissue glucose concentrations in six non-diabetic pigs as determined by glucose sensors implanted in this tissue. Figure 2 indicates electrode responses during and after a $12.5 \mathrm{~g}$ bolus of intravenous glucose, and Figure 3 shows the electrode responses after intravenous, shortacting insulin injection $(0.2 \mathrm{U} / \mathrm{kg})$. In each case, serial blood samples were also taken for estimation of glucose concentration by a conventional glucose oxidase-based analyser (YSI); the results are shown for comparison in the figures.

The mean \pm SEM baseline apparent subcutaneous tissue glucose concentration was $0.59 \pm 0.21 \mathrm{mmol} / 1$ before glucose and $1.5 \pm 0.27 \mathrm{mmol} / 1$ before insulin injection. The respective baseline blood glucose levels were $4.1 \pm 0.5$ and $5.4 \pm 0.6 \mathrm{mmol} / 1$. Following intravenous glucose administration (Fig. 2) the peak blood glucose value was at $1 \mathrm{~min}(11.5 \pm 1.1 \mathrm{mmol} / \mathrm{l})$ but the maximal tissue glucose recorded by the implanted sensor was at $13 \mathrm{~min}$ after glucose injection $(1.7 \pm 0.3 \mathrm{mmol} / 1)$. Nevertheless, subcutaneous electrode responses increased at virtually the same time as blood glucose concentrations, thereafter rising and subsequently falling more slowly than the blood changes. 

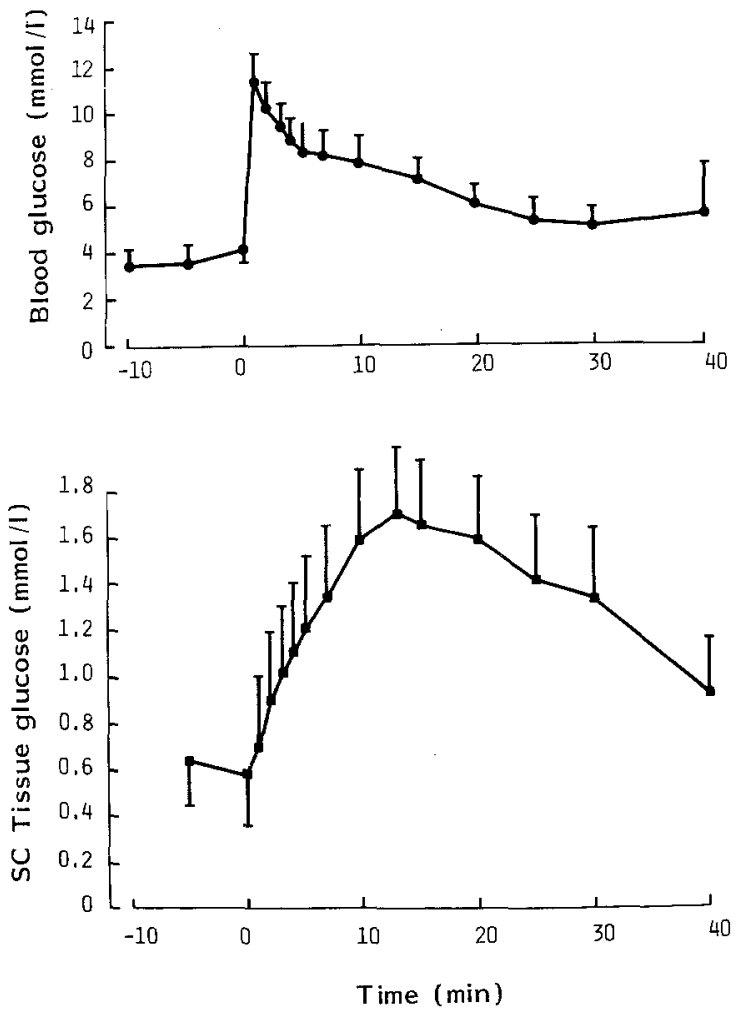

Fig. 2. Upper panel: mean \pm SEM blood glucose concentrations (YSI analyser) before and after intravenous glucose administration in six pigs. Lower panel: corresponding mean $\pm \mathrm{SEM}$ subcutaneous tissue glucose concentrations, as measured by the sensor ( $n=10$ electrodes)
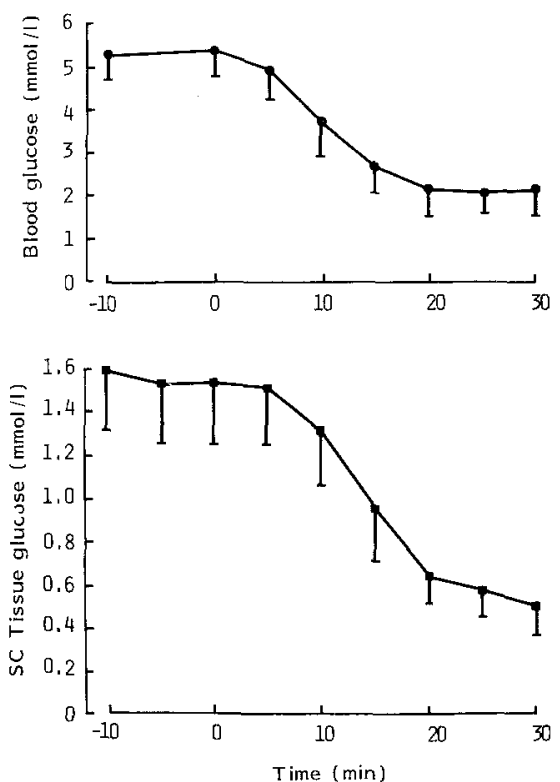

Fig. 3. Upper panel: mean \pm SEM blood glucose concentrations (YSI analyser) before and after intravenous insulin injection in six pigs. Lower panel: corresponding mean \pm SEM subcutaneous tissue glucose concentrations, as measured by the sensor ( $n=9$ electrodes)

After intravenous insulin administration (Fig. 3) the blood glucose concentration was significantly lower than the baseline value by $10 \min (p<0.05)$; subcutaneous electrode responses were significantly lower after $20 \min (p<0.002)$.

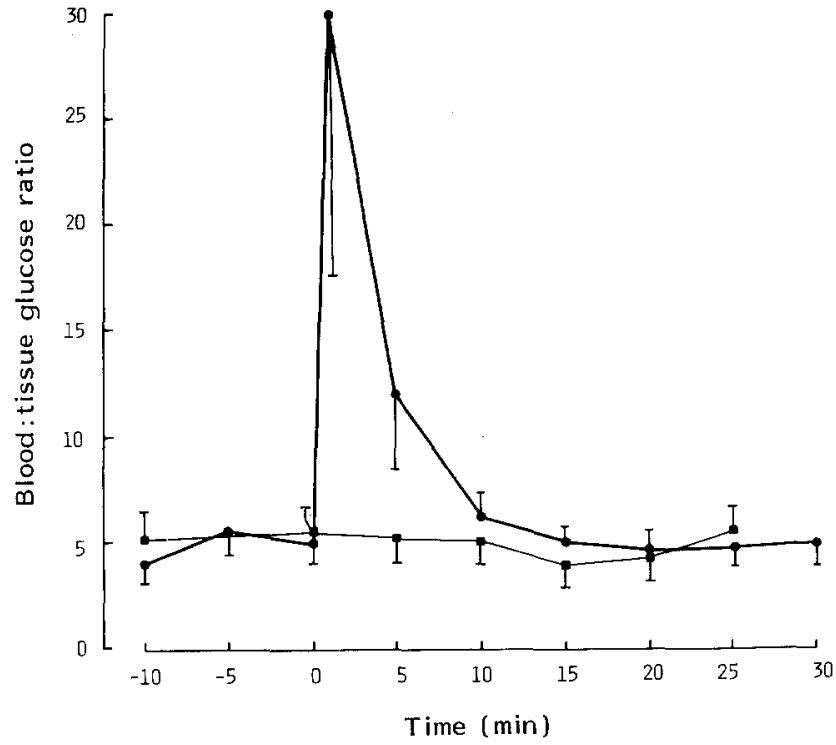

Fig.4. Mean \pm SEM blood: tissue glucose ratio before and after glucose (๑) and insulin administration

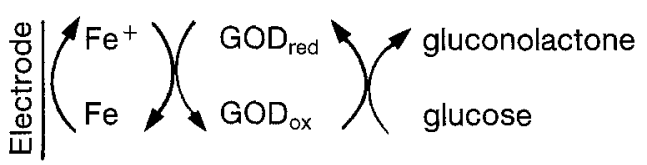

Fig.5. Reaction sequence for the glucose sensor. $\mathrm{Fe}, \mathrm{Fe}^{+}=$dimethylferrocene, dimethylferrocinium ion; GOD $=$ glucose oxidase (reduced and oxidised form)

The rate of fall of blood glucose concentration between $10 \mathrm{~min}$ and $20 \mathrm{~min}$ after insulin injection was $9.0 \pm 1.9 \mathrm{mmol} \cdot \mathrm{1}^{-1} \cdot \mathrm{h}^{-1}$ (mean $\left.\pm \mathrm{SEM}\right)$, and the rate of fall of apparent subcutaneous tissue glucose levels was $4.2 \pm 1.0 \mathrm{mmol} \cdot 1^{-1} \cdot \mathrm{h}^{-1}(p<0.05$, blood vs tissue $)$.

In experiments in which two electrodes were implanted in one animal, the mean $\pm S E M$ difference in glucose concentration recorded by the sensors at baseline was $0.49 \pm 0.14 \mathrm{mmol} / 1(n=7)$. The two electrodes always showed similar kinetics after glucose or insulin administration.

After insulin injection, the mean \pm SEM correlation coefficient between tissue and blood glucose concentrations for individual electrodes was $0.91 \pm 0.02$ with a regression equation, blood glucose $=0.27+(4.57 \times$ tissue glucose). After glucose injection, the relationship was less strong, $r=0.14$.

Figure 4 shows the mean \pm SEM ratio of blood: apparent tissue glucose concentration throughout both experiments, i. e. after intravenous glucose and insulin administration. Apart from a time period between 0 and 5 min after glucose injection, when blood glucose values were increasing very rapidly, the mean blood: tissue ratio was approximately constant at 4-6. After glucose administration, the ratio was significantly different from baseline at $1 \mathrm{~min}(p<0.005)$ but not at $5 \mathrm{~min}$ and at subsequent time points. 


\section{Discussion}

The major potential advantage of the ferrocene-mediated glucose sensor is that transfer of electrons from glucose to the base electrode occurs without the participation of oxygen. For an in vivo sensor this may be an important consideration, since changes in $\mathrm{PO}_{2}$ at the implantation site may interfere with electrode responses [10]. The reaction sequence for the sensor is shown in Fig. 5. The postulated mechanism of direct transfer of electrons via ferrocene is supported by our demonstration of a $98 \%$ reduction in current output when electrodes were constructed without the addition of ferrocene. The participation of hydrogen peroxide in the functioning of the sensor is also made unlikely by the previously reported oxygen insensitivity of the electrode $[8,9]$ and its low operating voltage of $160 \mathrm{mV}$ (cf $600 \mathrm{mV}$ for $\mathrm{H}_{2} \mathrm{O}_{2}$-detecting sensors [6]).

We recently adapted [9] the mediated electron transfer principle of Cass et al. [8] to produce a miniature, amperometric glucose sensor operating on a simple two-electrode system. In vitro studies showed that the sensor displayed linear responses to a glucose concentration of at least $20 \mathrm{mmol} / 1$, had a mean $90 \%$ response time of $68 \mathrm{~s}$ for a $5 \mathrm{mmol} / 1 \mathrm{step}$ increase in glucose and was only minimally affected by wide changes in $\mathrm{PO}_{2}$ $(2.0->60 \mathrm{kPa})$. Whilst not all electrodes that are constructed are stable enough for use, we found that $17 \%$ had no or only a slight drift over $17 \mathrm{~h}$ in $10 \mathrm{mmol} / \mathrm{l}$ glucose solution at $37^{\circ} \mathrm{C}$. The sensors used in the present work were constructed in the same way as our previous study and had similar operating characteristics.

In the present study we have, using these electrodes, tested the hypothesis that the subcutaneous tissue is a suitable site for monitoring diabetic control. We chose the pig as the experimental model since it is one of the few species which possesses subcutaneous tissue similar to that of man. Several previous studies of subcutaneously implanted glucose sensors have employed dogs [6, $7,10,11]$, in which the responses may not easily be extrapolated to the human situation. We also, in this study, showed that a surface electrocardiogram electrode functions well as a reference; results, indeed, were not different from experiments in which an implanted silver/silver chloride wire was used as the reference electrode (unpublished observations).

Our finding that the subcutaneous tissue glucose concentration was about $20 \%$ of the blood value compares with the results of Bessman et al. [10], who found that subcutaneous values (using a sensor) were about $50 \%$ of the blood; Abel et al. [7] reported sensor-determined subcutaneous levels which were $30-50 \%$ of those in blood in dogs, and Shichiri and Kawamori [12] showed that glucose levels in the subcutaneous tissue in the human were $25 \%$ lower than in the blood. Bessman et al. [10] pointed out that their glucose oxidase enzyme electrode, based on oxygen consumption, may have been affected by tissue $\mathrm{PO}_{2}$ and thus have given a spuri- ous reading for the subcutaneous tissue glucose concentration.

There is experimental evidence, however, that variations in oxygen are not major modulators of the output of the present glucose sensor $[8,9]$.

The unexpectedly low subcutaneous tissue glucose level may have a number of other explanations. Firstly, the electrodes were calibrated in buffered glucose solutions and it is not known how interstitial fluid alters this calibration. It is of note here that, in a previous study [9], we reported that albumin at a concentration of $80 \mathrm{~g} / \mathrm{l}$ did not alter electrode responses and that plasma glucose levels at and below euglycaemia were similar, when measured by the ferrocene glucose sensor and a standard laboratory method.

Another possibility is that the active area of the sensor is exposed to less fluid in vivo than in vitro. This is a difficult hypothesis to test. Furthermore, depletion layers around the sensor may account for errors and although stirring and the viscosity of the calibrating fluid [9] had no effect in vitro it cannot be excluded that the transport of glucose to the sensor in vivo is determined by different factors.

In the future, studies must confirm the true interstitial tissue glucose concentration by independent means. The experiments of Wolfson et al. [13] using, in non-diabetic baboons and/or rabbits, implanted capsules, dialysis sacks and membrane devices, showed the accumulation of fluid within these chambers with a glucose concentration of $2.8-6.4 \mathrm{mmol} / 1$. However, these values were not related to blood glucose concentrations.

The ratio of blood: subcutaneous tissue glucose concentration varied considerably between experiments in the present study (mean 5.2, range 1.8-14.7 at baseline). However, this ratio was approximately constant for a given study throughout the deliberate manipulations in blood glucose, except for the 5-10 min after bolus intravenous glucose injection, when blood glucose levels were markedly elevated. The maintenance of this ratio in a given animal supports the idea that the in vivo electrode drift is small during the course of the experiment. We conclude, also, that for an individual, calibration of implanted glucose sensors may have to be made in vivo (by simultaneous measurement of blood glucose and subcutaneous electrode response). On the basis of the present results, the use of an implanted sensor as an hypoglycaemia detector is feasible and may be the most important first goal of commercial sensor development.

The purpose of the present study was solely to explore the feasibility of subcutaneous sensing with the technology of the ferrocene-mediated sensor. The design and construction of the electrode we report here is probably unsuitable for widespread use in diabetic man and the important problems of biocompatibility, longterm stability, miniaturisation, shelf-life, cost, ease of manufacture in bulk, and reliability must be addressed in future work. We did not, for example, examine the histology of the implantation site, because of the short- 
term nature of the work. Also, the incorporation of the sensor in closed-loop insulin delivery systems will involve the development of more sophisticated algorithms and models relating various changes in subcutaneous and blood glucose concentrations under a variety of circumstances.

Acknowledgements. We thank Mr E V Plotkin, Dr W Beck and Professor M I Gurr for helpful advice and assistance with this project.

\section{References}

1. Updike SJ, Hicks GP (1967) The enzyme electrode. Nature 214: 986-988

2. Soeldner JS, Chang KW, Aisenberg S, Hiebert JM (1973) Progress towards an implantable glucose sensor and an artificial beta cell. In: Urquhart J, Yates FE (eds) Temporal Aspects of Therapeutics. Plenum, New York, pp 181-207

3. Gebhardt U, Luft G, Richter GJ, von Sturm F (1978) Development of an implantable electrocatalytic glucose sensor. Bioelectrochem. Bioenerget 5: 607-624

4. Turner APF, Pickup JC (1985) Diabetes mellitus: biosensors for research and management. Biosensors 1: 85-115

5. Pickup JC (1985) Biosensors: a clinical perspective. Lancet 2: 817-820

6. Shichiri M, Kawamori R, Yamasaki Y, Hakui N, Abe H (1982) Wearable-type artificial pancreas with needle-type glucose sensor. Lancet 2: 1129-1131

7. Abel P, Miller A, Fischer U (1984) Experience with an implantable glucose sensor as a prerequisite of an artificial beta cell. Biomed Biochim Acta 5: 577-584
8. Cass AEG, Davis G, Francis GD, Hill HAO, Aston WJ, Higgins IJ, Plotkin EV, Scott LDL, Turner APF (1984) Ferrocene-mediated enzyme electrode for amperometric determination of glucose. Anal Chem 56: 667-671

9. Claremont DJ, Penton C, Pickup JC (1986) Potentially-implantable, ferrocene-mediated glucose sensor. J Biomed Eng 8: 272-274

10. Bessman SP, Thomas LJ, Kojima H, Sayler DF, Layne EC (1981) The implantation of a closed-loop artificial beta cell in dogs. Trans Am Soc Art Int Org 27: 7-17

11. Shichiri M, Kawamori R, Goriya Y, Yamasaki Y, Nomura M, Hakui $\mathrm{N}$, Abe H (1983) Glycemic control in pancreatectomized dogs with a wearable artificial endocrine pancreas. Diabetologia 24: 179-184

12. Shichiri M, Kawamori R (1983) Feasibility of a needle-type glucose sensor and the wearable artificial endocrine pancreas system in human diabetic subjects. In: Irsigler K, Kritz H, Lovett R (eds) Diabetes treatment with implantable insulin infusion systems. Urban \& Schwarzenberg, Munich, pp 224-230

13. Wolfson SK, Tokarsky JF, Krupper MA (1982). Glucose concentration at possible sensor sites. Diabetes Care 5: 162-165

Received: 16 June 1986

and in revised form: 26 September 1986

Dr. J.C. Pickup

Division of Chemical Pathology

United Medical \& Dental Schools

Guy's Hospital Campus

London SE1 9RT

UK 